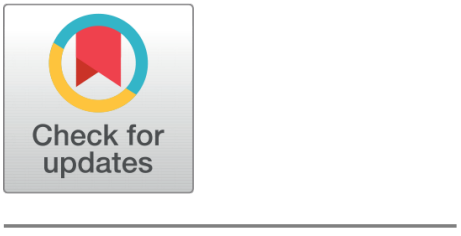

OPEN ACCESS

Received: 13.03.2021

Accepted: 22.04 .2021

Published: 12.05 .2021

Citation: Alshmemri MS, Tayyib NA, Alsolami FJ, Alsulami SA, Ramaiah P, Asfour HI, Lindsay GM (2021) Exploring the cultural competency of Expatriate Nurses working in Saudi Arabia. Indian Journal of Science and Technology 14(17): 1347-1353. https://doi.org/ 10.17485/IJST/v14i17.437

*orresponding author.

Tel: +966534318424

aravindanadar@gmail.com

Funding: None

Competing Interests: None

Copyright: (c) 2021 Alshmemri et al. This is an open access article distributed under the terms of the Creative Commons Attribution License, which permits unrestricted use, distribution, and reproduction in any medium, provided the original author and source are credited.

Published By Indian Society for Education and Environment (iSee)

ISSN

Print: 0974-6846

Electronic: 0974-5645

\section{Exploring the cultural competency of Expatriate Nurses working in Saudi Arabia}

\author{
Mohammad S Alshmemri' ${ }^{1}$, Nahla A Tayyib ${ }^{1}$, Fatmah J Alsolami ${ }^{1}$, \\ Sanaa A Alsulami ${ }^{1}$, Pushpamala Ramaiah ${ }^{1}$, , Hayam I Asfour ${ }^{1}$, \\ Grace M Lindsay 1 \\ 1 Faculty of Nursing, Umm Al-Qura University, Mecca, Saudi Arabia. Tel.: +966534318424
}

\section{Abstract}

Objective: The research was to undertake a descriptive survey of International nurses working in a different hospital in Saudi Arabia to explore cultural competency. Methods: A prospective cross-sectional survey design was utilized. The convenient sample included 736 expatriate nurses working in several healthcare settings in Saudi Arabia, on one occasion using a prevalidated self-assessment questionnaire. Findings: Current study reported that most nurses were Indians and Philippino Nurses with $51.5 \%$ and $42.1 \%$, respectively. Expatriate nurses have shown a higher-level competence in a. Awareness and sensitivity b. Behavior c. Patient-centered communication. A significant statistical association was found between cultural competence and the selected demographic characteristics. Novelty: Care provider and care receiver's culture impacts the healthcare delivery system's contemporary philosophy. The institutional guidelines and the appropriate professional support would be the core context of generating culturally competent care to enhance quality care management.

Keywords: Cultural diversity; quality care; competency; nurses; patient satisfaction

\section{Introduction:}

Culture is a set of established beliefs held by a particular group of people handed down from generation to generation. To disseminate the beliefs, values, and perceptions are unique to the specific culture ${ }^{(1)}$. Today's healthcare trend leans toward being more inclusive of personal and cultural preferences that demand a knowledgeable, genuine, and relevant response from caregivers ${ }^{(2)}$. The crux that emphasizes competent care's dimension is recognizing beliefs and culture before caring for others. Incorporating three significant domains, awareness, behavior, and communication makes these interactions more accessible, productive, and successful ${ }^{(3)}$. Cultural competency in Saudi Arabia is a complex paradigm in which culture plays the most significant challenge to evolving nursing practices' effective delivery. Competent transcultural health care services with the appropriate interventions have been identified as essential for delivering safe health care in the kingdom and internationally ${ }^{(4)}$. 
Diversity within specific workplaces is not a wonder in any healthcare institution. Clients and families most likely act and think differently compared to their care providers. Nevertheless, in Saudi Arabia (SA), a culture influenced by Islam, there are particular challenges because of the values they strongly embrace in their honor and integrity ${ }^{(5)}$. The necessity of cultural competency is more likely to generate confidence than overarches between care providers and receivers ${ }^{(6)}$. Also, the initiative seeks cultural Awareness as programs that could facilitate expatriate nurses in optimizing standards and enhancing favorable influences and efficiency upon quality care ${ }^{(7)}$. The delivery of contextually informed orientation programs to new employees forms an essential component of achieving the gap in cultural assimilation. Nurse educators have an integral role in identifying new employees' cultural and religious knowledge and designing programs to address these needs ${ }^{(8)}$.

The Cultural Competency challenges among Expatriate Nurses Working in the Kingdom of Saudi Arabia were explored among nurses working in Riyadh, which highlighted the concepts of religion, culture, and language are considered to be crucial. Several themes emerged from the expatriate nurses' experience of providing the expected care to religious groups, such as the barriers to carrying out nursing duties due to religious, cultural, and language factors ${ }^{(9)}$. As perceived by expatriate nurses, the reality in Islam's beliefs and practices may affect the patient's health care if such values are not handled with the feasible perception and integration ${ }^{(10)}$.

Lack of expatriate nurses' orientation to religious knowledge and practices is the paramount concern that would hinder the quality. In a study, nurses acknowledged the importance of language when caring for patients, and it was significantly associated with rendering proper care. Although nursing education in Saudi Arabia has gone through significant developments, it is still a profession with societal and cultural stigmas ${ }^{(11)}$.

The distinctiveness of Saudi Arabians' culture and the control by foreigners with scant knowledge about their culture signifies the challenges of executing culturally competent care. A study insists on understanding and accepting the variations that define the community from different cultural settings ${ }^{(12)}$. If nurses anchor and perceive others' cultural attributes well, they will be well placed to care for them appropriately. The collection of attitudes, policies and behaviors should not be forgotten because it might enable nurses and others to work efficiently within transcultural settings ${ }^{(13)}$. Consequently, nurses within this culturally diverse environment struggled in terms of their cultural expectations and those of the dominant Saudi culture ${ }^{(14)}$. Besides, Literature shows misunderstandings and conflicts with patients through the lack of cultural communication skills with them in a culturally appropriate manner, giving rise to disputes and stress ${ }^{(15)}$. Endangering patient care and increased the risk of errors, the consequences of which could prove fatal. Each patient, regardless of the environment, should be offered valuable and compassionate care. Hence the authors decided to explore the cultural diversity perceptions among ex-pat nurses working in Saudi Arabia to understand the current developments in quality care delivery.

\section{Materials and Methods}

A prospective cross-sectional exploratory survey design was used, where data were collected on one occasion using a selfassessment questionnaire. The sample size was calculated as 736 using the previous research studies of the same field. The inclusion criteria were the expatriate nurses in all healthcare settings of different regions. Saudi nationals were excluded from participating in this research. Data collection and research instrument had two sections as follows:

1. Socio-demographic data.

2. Cultural competency associated domains: a Awareness b Behavior c Practice Orientation.

The study tool utilized the Individual Assessment of Cultural Competence, developed by the AUD multicultural council Tawara

$\mathrm{D}$, and Inocian EP et al. ${ }^{(16)}$. The survey tool was validated by circulating the questionnaire to the experts of quality in nursing education. A convenient sampling technique was adopted to gather data from the nurses working in the hospital in a different region of Saudi Arabia.

\section{Research Questions}

1. Does Culturally competent care provide by expatriate nurses, and what is the level of competency?

2. Is there a statistically significant association between demographic characteristics and competency level regarding Awareness, behaviours, and orientation?

The descriptive survey was circulated through the research assistant's relevant clinical areas, consented to the same day before filling up the survey. Saudi National nurses were excluded from the study. A pilot study was performed among the $10 \%$ of the study participants that were executed to test the study design's performance characteristics and capabilities, measures, procedures, recruitment criteria, and operational strategies considered for implementing this study. The collected 
data underwent analysis using descriptive statistics such as mean, median, standard deviation, inferential statistics of chi-square, Mann-Whitney test, and Kruskal-Wallis H test. Each cultural domain's mean value of 2.5 and 3.5 was attributed to competent and high-level competency, respectively.

\section{Results}

\section{Respondents Profile}

Table 1 denotes the participants regarding their age, gender, years of experience, qualification, healthcare setting region, current role, and nationality. The majority of the nurses were in the age group of 29-34 years 289 (39.3\%), whereas $41-50$ were 157 (21.3\%). The group 23 - 28 years was 138 (18.8\%) and the age group of 41-50 years belongs to 157 nurses (21.3\%). The lessor number of participants was 51-60 years, with 36 (4.9\%). The participants were predominantly female, with 718 (97.6\%). 289 $(39.3 \%)$ charge nurses, $157(21.3 \%)$ Nurse educators, $116(15.8 \%)$ quality nurses, and five or less than five percent were from the rest of the category were from the clinical nurse, nurse manager, nurse-midwife, etc.

In terms of experience, $292(39.7 \%)$ of the nurses have less than a year, $262(35.6 \%)$ have more than ten years, and five to ten years are 108 nurses (14.7\%). Indian nurses were the majority of the participants, with 379 (51.5\%). The Philippino nurses contributed to be 310 (42.1\%). The remaining participants were from other countries such as Pakistan, Egypt, Sudan, Yemen, Bangladesh, Indonesia, and Jordan, with less than a probable value of five percent.

Table 1. Participants' Profile Distribution

\begin{tabular}{|c|c|}
\hline Gender & No (\%) \\
\hline Male & $18(2.4)$ \\
\hline Female & $718(97.6)$ \\
\hline \multicolumn{2}{|l|}{ Qualification } \\
\hline Associate Degree & $91(12.4)$ \\
\hline Bachelor Degree & $607(82.5)$ \\
\hline Masters Degree & $31(4.2)$ \\
\hline Ph.D. or DNP & $7(1)$ \\
\hline \multicolumn{2}{|l|}{ Years of Experience } \\
\hline $1->3$ Years & $2(.3)$ \\
\hline 3 - >5 years & $72(9.8)$ \\
\hline $5-10$ Years & $108(14.7)$ \\
\hline More than 10 Years & $262(35.6)$ \\
\hline Less than 1 Years & $292(39.7)$ \\
\hline \multicolumn{2}{|l|}{ Location } \\
\hline West region & $183(24.9)$ \\
\hline East & $155(21.1)$ \\
\hline South & $199(27)$ \\
\hline North & $85(11.5)$ \\
\hline Central & $114(15.5)$ \\
\hline \multicolumn{2}{|l|}{ Age } \\
\hline $23-28$ & $138(18.8)$ \\
\hline $29-34$ & $289(39.3)$ \\
\hline $35-40$ & $116(15.8)$ \\
\hline $41-50$ & $157(21.3)$ \\
\hline $51-60$ & $36(4.9)$ \\
\hline \multicolumn{2}{|l|}{ Current Role } \\
\hline Registered Nurses (Staff nurses) & $138(18.8)$ \\
\hline Charge Nurse & $289(39.3)$ \\
\hline Quality nurse & $116(15.8)$ \\
\hline Nurse educator & $157(21.3)$ \\
\hline Clinical Nurse & $21(2.9)$ \\
\hline Nurse Manager and head nurse & $30(4.1)$ \\
\hline Staff midwife & $40(5.4)$ \\
\hline Nurse Assistant & $6(.8)$ \\
\hline Infection control nurse & $5(.7)$ \\
\hline
\end{tabular}




\begin{tabular}{|c|c|}
\hline \multicolumn{2}{|l|}{ Table 1 continued } \\
\hline Dialysis nurse & $5(.7)$ \\
\hline $\begin{array}{l}\text { Assistant Nursing Director, Nursing Director, Nursing Coordinator, Clinical } \\
\text { Instructor, Nurse technician, Dental Assistant (Each) }\end{array}$ & $1(.1)$ \\
\hline \multicolumn{2}{|l|}{ Nationality } \\
\hline Philippines & $310(42.1)$ \\
\hline Indian & $379(51.5)$ \\
\hline Pakistani & $6(.8)$ \\
\hline Egyptian & $13(1.8)$ \\
\hline Indonesia & $2(.3)$ \\
\hline Sudani & $19(2.6)$ \\
\hline Bangladeshi, Jordanian, & $1(.1)$ \\
\hline \multicolumn{2}{|l|}{ And Yemeni (Each) } \\
\hline Tunisian & $4(.5)$ \\
\hline
\end{tabular}

\section{Assessment of Cultural competency items of Awareness and behavior}

Table 2 depicts the expatriate nurses' cultural aspect in Cultural Awareness and sensitivity working in Saudi Arabia. The nurses scored an overall higher level of competence with the mean \pm SD (3.62 \pm .464$)$ in rendering care to the patient with favorable and supportive skills. Cultural competency was evident with their Awareness of the diversity of culture at the workplace (3.94 \pm .755$)$. They know the value of assessing various aspects of cultural diversity that need to be evaluated for each group and organization (3.94 \pm .755$)$. Spirituality and cultural beliefs as an essential aspect of many cultural groups were perceived at a level of (4.08 \pm .717$)$. Nurses understand that people from different cultures may define health care differently (3.78 \pm .839$)$ and have more interest in understanding that knowing about other cultural groups helps direct my work with individuals, families, groups, and organizations (3.99 \pm .705$)$. The majority of them enjoy working with people who are culturally different $(3.96 \pm .696)$.

Table 2. Assessment of Cultural competency items of Awareness and behavior

\begin{tabular}{|c|c|c|}
\hline Cultural competency items: Awareness & Mean \pm SD & Interpretation \\
\hline Race is the significant determining factor in a person's culture. & $3.3 \pm 1.284$ & Competent \\
\hline The people with common cultural backgrounds think alike. & $3.29 \pm 1.028$ & Competent \\
\hline Many aspects of culture influence health and health care. & $3.89 \pm .758$ & Highly Competent \\
\hline The cultural diversity aspect needs to be assessed for each group and organization. & $3.94 \pm .755$ & Highly Competent \\
\hline $\begin{array}{l}\text { It is unnecessary to assess their personal preferences for health services unless I do } \\
\text { not know their culture. }\end{array}$ & $2.66 \pm 1.162$ & Competent \\
\hline Spirituality and cultural beliefs are essential aspects of many cultural groups. & $4.08 \pm .717$ & Highly Competent \\
\hline Individual people may identify with more than a cultural group. & $3.62 \pm .830$ & Highly Competent \\
\hline The language barrier is the only difficulty for recent immigrants to KSA. & $3.4 \pm 1.097$ & Competent \\
\hline $\begin{array}{l}\text { Different cultural backgrounds people may define the concept of Health care in } \\
\text { another way. }\end{array}$ & $3.78 \pm .839$ & Highly Competent \\
\hline $\begin{array}{l}\text { Knowing about various cultural groups helps direct my work with individuals, } \\
\text { families, groups, and organizations. }\end{array}$ & $3.99 \pm .705$ & Highly Competent \\
\hline Enjoy working with people who culturally differ. & $3.96 \pm .696$ & Highly Competent \\
\hline Total & $3.62 \pm .464$ & Highly Competent \\
\hline
\end{tabular}

\section{Assessment of Cultural competency items of behavior}

Table 3 Concerning the nurses' behavior in rendering quality care with cultural competency skills were explored with the value of Mean \pm SD of 3.82 \pm .744 and interpreted as a high level of competency. The highest level of the mean score was obtained for the item regarding adaptation to clients and families' preferences (4.03 \pm .635$)$, followed by the object representing learning opportunities from coworkers about the people with different cultural heritages $(4.01 \pm .633)$. On the contrary, the lowest score was $3.41 \pm .933$, related to the resources, books, and other materials available to help clients and families from different cultures. Most nurses welcome coworkers' feedback about how they relate to others with different cultures (4.02 \pm .690$)$. 
Table 3. Assessment of Cultural competency items of behavior

\begin{tabular}{|c|c|c|}
\hline Cultural competency items: Behavior & Mean \pm SD & Interpretation \\
\hline Cultural assessment is included when I do client or family evaluation & $3.85 \pm .770$ & Highly Competent \\
\hline $\begin{array}{l}\text { When I work with a new client and family in my practice, I seek information on cultural } \\
\text { needs }\end{array}$ & $3.9 \pm .679$ & Highly Competent \\
\hline $\begin{array}{l}\text { I have resources, books, and other materials available to help clients and families from } \\
\text { different cultures. }\end{array}$ & $3.41 \pm .933$ & Competent \\
\hline A variety of sources are required to learn about the cultural heritage of other people & $3.71 \pm .792$ & Highly Competent \\
\hline I seek clients and families to tell me about their explanations of health and illness & $3.88 \pm .711$ & Highly Competent \\
\hline $\begin{array}{l}\text { I ask clients and families to tell about their expectations for health services (expectations } \\
\text { of care) }\end{array}$ & $3.9 \pm .713$ & Highly Competent \\
\hline Avoid using generalizations to the stereotype community. & $3.76 \pm .803$ & Highly Competent \\
\hline Recognize potential barriers to service that different people might encounter & $3.85 \pm .685$ & Highly Competent \\
\hline Obstacles are removed for people of different cultures when I identify such obstacles & $3.82 \pm .742$ & Highly Competent \\
\hline $\begin{array}{l}\text { Obstacles are removed for people of different cultures when clients and families identify } \\
\text { such barriers to me }\end{array}$ & $3.75 \pm .758$ & Highly Competent \\
\hline $\begin{array}{l}\text { I welcome feedback from clients and their families about how I relate to others with } \\
\text { different cultures }\end{array}$ & $3.97 \pm .690$ & Highly Competent \\
\hline I welcome feedback from coworkers about how I relate to others with different cultures & $4.02 \pm .690$ & Highly Competent \\
\hline I find ways to adapt my services to my clients and families preferences & $4.03 \pm .635$ & Highly Competent \\
\hline I document cultural assessment & $3.63 \pm .867$ & Highly Competent \\
\hline I document the adaptations I make with clients and their families & $3.7 \pm .817$ & Highly Competent \\
\hline Learn from my coworkers about the people with diverse cultural heritage. & $4.01 \pm .633$ & Highly Competent \\
\hline Total & $3.82 \pm .744$ & Highly Competent \\
\hline
\end{tabular}

\section{Cultural competency responses in terms of practice orientation and decision making}

Table 4 The impact of clinical decision-making skills among 736 nurses in association with the treatment options to comply with nurses' cultural adaptation in the new setting documented $99 \%(728)$ nurses adhere to the expected challenges in the decisionmaking process while dealing with patient and families. The remaining eight nurses reported that they seldom follow such cultural rights of the patients and families. Concerning the items of practice orientation,"When there are various treatment options, how do you make an effort to give the client and their family control over their treatment?" The responses from threefourths of the participants (74,5\%) always agreed to follow and often, whereas only $24.5 \%$ (188) nurses sometimes expressed, seldom, and never. The critical item on "When there are various treatment options, how often you ask the client and their family to take responsibility for their treatment?" was $75.5 \%$ (557) nurses with the maximum proportion with a high level of competency.

Table 4. Cultural Competency Items: Practice Orientation

\begin{tabular}{llllll}
\hline Cultural competency items: Practice orientation & Always & Often & Sometimes & Seldom & Never \\
\hline $\begin{array}{l}\text { When there are various treatment options, how } \\
\text { often do you give the client and their family a } \\
\text { choice when deciding? }\end{array}$ & $362(49.2)$ & $226(30.7)$ & $126(17.1)$ & $9(1.2)$ & $13(1.8)$ \\
$\begin{array}{l}\text { When there are various treatment options, how } \\
\text { do you make an effort to give the client and their }\end{array}$ & $295(40.1)$ & $253(34.4)$ & $154(20.9)$ & $17(2.3)$ & $17(2.3)$ \\
$\begin{array}{l}\text { family control over their treatment? } \\
\begin{array}{l}\text { When there are various treatment options, how } \\
\text { often you ask the client and their family to take } \\
\text { responsibility for their treatment? }\end{array}\end{array}$ & $343(46.6)$ & $214(29.1)$ & $126(17.1)$ & $27(3.7)$ & $26(3.5)$
\end{tabular}




\section{Significant difference in the competency and demographic profile}

According to the grouping of the participants' age, education, and nationality to find out the significant association with cultural competency, it was found that the chi-square statistical test revealed the statistical association at $\mathrm{p}$-value $<.05$. It was evident that the older nurses have better Awareness and behaviors in delivering the standard care. The Kruskal- Wallis (non-parametric) analysis revealed a statistical difference between the length of service and cultural competency at a p-value less than .05. A MannWhitney $U$ test showed the significant hypothetical differences of cultural competency with male and female staff nurses and the $\mathrm{p}$-value $=<.05$.

\section{Discussion}

This project explored the various domains of cultural competencies, such as Awareness, behavior, and practice orientation of nurses working in different units in different hospitals in Saudi Arabia. Our reports revealed and aligned with the evidencebased cultural competency and associated interventions that have shown the enhanced competency in recent years ${ }^{(17)}$.

The cultural competency study results reflected that nurses are more competent and have an exponential interest in increasing their knowledge with the more excellent attitude of caring for patients working in diverse cultural backgrounds ${ }^{(18)}$. This report is in line with similar studies among nurses in the same country, with a mean value of 3.15. Study findings authenticate that expatriate nurses possess a greater recognition, sensitivity, and Awareness of executing the care that can satisfy the patients with the positive outcome. Our study demonstrated that the integral and intrinsic aspect of delivering quality care is vital amid cultural diversity. On the contrary, Abudari G et al. explored a survey that nurses lacked specific artistic skills due to a lack of cultural competency awareness and an unavailable education support system ${ }^{(19)}$.

The highest mean of the cultural competency items regarding understanding culture was spirituality, which is perceived as an essential aspect of many cultural groups (4.08 \pm .717$)$. Competency care can facilitate nurses' communication in interacting with patients and families, which has been chosen with obvious communication strategies ${ }^{(4)}$. Even a unique word that aligns with cultures can convey multiple messages with plenty of advantages in the dominant cultural heritage community. Our study documented the nurses' understanding level, with the primary assessment (3.85 \pm .77$)$ capabilities with recursiveness $(3.71 \pm .792)$ to permit them to receive favorable responses on caring patients with diversified culture.

Nurses had to endure various difficult experiences while adapting to and coping in a new artistic, religious, physical, emotional, and professional environment ${ }^{(16)}$. A study conducted in Saudi Arabia recognized the prevalence of depression, anxiety, and stress among expatriate nurses in Saudi Arabia. It assessed how dissatisfaction with salary, workload, and teamwork, individually and in combination, was associated with those conditions. The conclusive statement said that Hospital and nursing administrators should identify specific aspects of workload and teamwork and offer solutions to reduce nurses' psychological distress ${ }^{(14)}$. A snapshot on the degree of spiritual climate perception may provide insight into the elements that may need improvement and become a basis for creating health and nursing policies directed towards creating a spiritually accepting and respecting clinical workplace. Hospitals are recommended to amend protocols to implement interventions geared towards creating a spiritually-friendly environment ${ }^{(7)}$. Hospitals are encouraged to create a safe place where nurses can express their spirituality at ease regardless of preference or religious denomination. Hospitals may provide spiritual education as part of staff welfare. Managers may also focus on nurses' existential religious concerns, especially for spiritually-sensitive environments such as Saudi Arabia ${ }^{(12)}$.

Nurses remain respectful when they overcome cultural biases by recognizing that they have appropriate knowledge, attitude, and communication to render culturally accepted care ${ }^{(14)}$. Particularly, Nurses' practice in the kingdom must incorporate cultural needs and beliefs into their nursing practice to provide individualized care for the client and appropriate to their needs ${ }^{(4)}$.

From a nursing perspective, the notion of employee satisfaction is about more than simply providing people with a job and a salary ${ }^{(12)}$. Nurses expressed that they could ask clients and families to tell about their healthcare expectations (expectations of care) with high-level cultural skills (3.88土.711). Moreover, cultural competency awareness supports them in recognizing $(3.85 \pm .685)$ the potential barriers and removing the obstacles $(3.82 \pm .742)$ to serve diversified people. The previous study findings reported the relationship between the quality of life and work turnover in Saudi Arabia, suggesting that the nurses were dissatisfied with their work-life, with almost $40 \%$ indicating a turnover intention from their current primary health centers. Lack of information, skills, and practice on culture could cause such consequences ${ }^{(8)}$. Researchers demonstrate with the well-evident reports that institutional orientation, training, Awareness, and support system could revamp the effective means of improving culturally challenging efficient care. 


\section{Conclusion}

In today's health care organizations, nurses and other health care professionals have the professional responsibility to be sensitive to their clients' cultural values and beliefs. This study's reports bring a new horizon on the higher competency level by revalidation of their better Awareness, practice, and orientation towards caring patients in diversified cultures. Nurses' cultural knowledge's innovative favorable competency skills can not be generalized as the survey was performed in one nation and with the particular religious groups of patients interaction. Further studies could be done to interpret the multicultural background.

\section{References}

1) Almalki MJ, FitzGerald G, Clark M. The relationship between quality of work life and turnover intention of primary health care nurses in Saudi Arabia. BMC Health Services Research. 2012;12(1):1-11. Available from: https://dx.doi.org/10.1186/1472-6963-12-314.

2) Murcia SEA, Lopez L. The experience of nurses in care for culturally diverse families: A qualitative meta-synthesis. Revista Latino-Americana de Enfermagem. 2016;24(e2718). Available from: https://dx.doi.org/10.1590/1518-8345.1052.2718.

3) Nurse.org. How to care for patients from different culture? . 2020.

4) Almutairi A, McCarthy A. A multicultural nursing workforce and cultural perspectives in Saudi Arabia: An overview. The Health. 2012;3(3):71-74. Available from: https://eprints.qut.edu.au/57066/.

5) Al-Hanawi MK, Khan SA, Al-Borie HM. Healthcare human resource development in Saudi Arabia: emerging challenges and opportunities-a critical review. Public Health Reviews. 2019;40(1):1-16. Available from: https://dx.doi.org/10.1186/s40985-019-0112-4.

6) O'Brien EM, Donnell CO, Murphy J, Brien BO, Markey K. Intercultural readiness of nursing students: An integrative review of evidence examining cultural competence educational interventions. Nurse Education in Practice. 2021;50:1-16. Available from: https://dx.doi.org/10.1016/j.nepr.2021.102966.

7) Tia MB, Aziato L, Dzansi G. Health system factors influencing nurses' ethical-decision making for postoperative pain management in Ghana. International Journal of Africa Nursing Sciences. 2020;13:1-7. Available from: https://dx.doi.org/10.1016/j.ijans.2020.100257.

8) Al-Yateem N, AlYateem S, Rossiter R. Cultural and Religious Educational Needs of Overseas Nurses Working in the Kingdom of Saudi Arabia and the United Arab Emirates. Holistic Nursing Practice. 2015;29(4):205-215. Available from: https://dx.doi.org/10.1097/hnp.0000000000000095.

9) Alosaimi DN, Ahmad MM. The Challenges of Cultural Competency Among Expatriate Nurses Working in Kingdom of Saudi Arabia. Research and Theory for Nursing Practice. 2016;30(4):302-319. Available from: https://dx.doi.org/10.1891/1541-6577.30.4.302.

10) Paric M, Kaihlanen AM, Heponiemi T, Czabanowska K. Nurse teacher's perceptions on teaching cultural competence to students in Finland: a descriptive qualitative study. Nurse Education Today. 2021;99:1-7. Available from: https://dx.doi.org/10.1016/j.nedt.2021.104787.

11) Oakley S, Grealish L, Amouri SE, Coyne E. The lived experience of expatriate nurses providing end of life care to Muslim patients in a Muslim country: An integrated review of the literature. International Journal of Nursing Studies. 2019;94:51-59. Available from: https://dx.doi.org/10.1016/j.ijnurstu.2019. 03.002 .

12) Felemban E, O’Connor M, McKenna L. Cultural View of Nursing in Saudi Arabia. Middle East Journal of Nursing. 2014;8(4):8-14. Available from: https://dx.doi.org/10.5742/mejn.2014.92587.

13) Saquib N, Zaghloul MS, Saquib J, Alhomaidan HT, Al-Mohaimeed A, Al-Mazrou A. Association of cumulative job dissatisfaction with depression, anxiety and stress among expatriate nurses in Saudi Arabia. Journal of Nursing Management. 2019;27(4):740-748. Available from: https://dx.doi.org/10.1111/ jonm.12762.

14) Al-Yateem N, AlYateem S, Rossiter R. Cultural and Religious Educational Needs of Overseas Nurses Working in the Kingdom of Saudi Arabia and the United Arab Emirates. Holistic Nursing Practice. 2015;29(4):205-215. Available from: https://dx.doi.org/10.1097/hnp.0000000000000095.

15) Alshammari M, Duff J, Guilhermino M. Barriers to nurse-patient communication in Saudi Arabia: an integrative review. BMC Nursing. 2019;18(61):1-10. Available from: https://dx.doi.org/10.1186/s12912-019-0385-4.

16) Inocian MEP, Attalah M, Moufleh M, Faden M, Eid S. Cultural competency among expatriate nurses in Saudi Arabia. International Journal of Nursing. 2015;4(1).

17) Ramaiah P, Tayyib NA, Alsolami FJ, Lindsay GM, Asfour HI. Health Professionals Dynamic Role Amid COVID-19: Nursing Perspectives. Journal of Pharmaceutical Research International. 2020;32(22):93-100. Available from: https://dx.doi.org/10.9734/jpri/2020/v32i2230776.

18) Murcia SEA, Lopez L. The experience of nurses in care for culturally diverse families: A qualitative meta-synthesis. Revista Latino-Americana de Enfermagem. 2016;24(e2718):1-11. Available from: https://dx.doi.org/10.1590/1518-8345.1052.2718. doi:10.1590/1518-8345.1052.2718.

19) Abudari G, Hazeim H, Ginete G. Caring for terminally ill Muslim patients: Lived experiences of non-Muslim nurses. Palliative and Supportive Care. 2016;14(6):599-611. Available from: https://dx.doi.org/10.1017/s1478951516000249. 